\title{
Perbandingan Kejadian Post Partum Blues Pada Ibu Nifas Di Wilayah Pedesaan Dan Wilayah Perkotaan
}

\author{
Samria $^{1^{*}}$, Indah Haerunnisa ${ }^{2}$ \\ ${ }^{1,2}$ STIKES Bina Generasi Polewali Mandar, Jl. Mr. Muh. Yamin No 195 Manding, Polewali Mandar, Sulawesi Barat, \\ 91315, Indonesia \\ 1samria923@gmail.com*, ${ }^{2}$ ndah910@gmail.com \\ *corresponding author \\ Tanggal Submisi: 16 Maret 2021, Tanggal Penerimaan: 8 April 2021
}

\begin{abstract}
Abstrak
Penelitian ini bertujuan untuk mengetahui perbandingan kejadian post partum blues pada ibu nifas di wilayah kerja Puskesmas Allu dan ibu nifas di wilayah kerja Puskesmas Pekkabata. Metode penelitian menggunakan desain penelitian deskriptif komparatif dan pendekatan cross-sectional. Jumlah sampel sebanyak 40 orang. Pengambilan sampel menggunakan kuesioner Edinburgh Postnatal Depression Scale (EPDS) yang telah baku. Hasil analisa hubungan kedua variabel dengan menggunakan uji statistik chi-square didapat signifikansi dari hubungan kedua variabel tersebut adalah $\mathrm{p}=0,000<\alpha(0,05)$.
\end{abstract}

Kata kunci: post partum blues; pedesaan; perkotaan

\section{Comparison Of The Incidence Of Post Partum Blues In Postpartum Mothers}

\begin{abstract}
This study aims to determine the comparison of the incidence of post partum blues in postpartum mothers at Allu Community Health Center and the postpartum mother at Pekkabata Health Center. The research method used a comparative descriptive research design and a cross sectional approach. The number of samples is 40 people. Sampling was using the standard Edinburgh Postnatal Depression Scale (EPDS) questionnaire. The results of the analysis of the relationship between the two variables was using the chi-square statistical test showed that the significance of the relationship between the two variables was $p=0.000<\alpha(0.05)$.
\end{abstract}

Keywords: post partum blues; rural; urban

\section{PENDAHULUAN}

Post partum blues adalah keadaan seorang ibu yang mengalami perasaan tidak nyaman setelah persalinan yang berkaitan dengan hubungan ibu dan bayinya atau dengan dirinya sendiri. Saat plasenta dikeluarkan pada serangkaian proses 
persalinan terjadi perubahan hormon yang melibatkan progesteron, dan estrogen dalam tubuh seorang wanita yang dapat mempengaruhi kondisi fisik, mental dan emosional ibu (Astuti, 2019).

Angka kejadian post partum blues di Asia cukup tinggi dan sangat bervariasi antara $26-85 \%$, sedangkan di Indonesia angka kejadian post partum blues antara 50-70\%. Jika post partum blues dibiarkan, dapat berlanjut menjadi depresi pasca melahirkan. Berbagai faktor yang dapat melatarbelakangi post partum blues adalah dukungan keluarga, pengetahuan, status kehamilan danjenis persalinan (Hidayat, 2014).

Depresi post partum sering terjadi pada masa adaptasi psikologis ibu masa nifas, walaupun insidensinya sulit untuk diketahui secara pasti namun diyakini 1015\% ibu melahirkan mengalami gangguan ini (Maryunani, 2017). Gejala baby blues ditandai dengan reaksi depresi atau sedih, menangis, mudah tersinggung, cemas, perasaan yang labil, cenderung menyalahkan diri sendiri, gangguan tidur dan gangguan nafsu makan (Ariyani, 2014). Penyebab post partum blues tidak dapat ditentukan secara pasti namun diduga dipengaruhi antara lain dikarenakan faktor internal dan faktor eksternal (Bahiyatun, 2009).

Dasar karakteristik calon peneliti juga pada penelitian ini berawal dari melihat pentingnya dukungan dan informasi menurunkan kejadian post partum blues. Pengamatan pengamatan yang telah dilakukan peneliti melalui fenomena post partum berawal melihat hasil survey awal penelitian, membandingan kejadian post partum blues didaerah perdesaan dan perkotaan yang terdapat perbedaan. Diperdesaan yang notabene masyaraat tidak bekerja di luar rumah bagi kaum hawa dan diperkotaan cenderung sibuk dengan pekerjaan dan kegiatan, selain itu juga diketahui bahwa didesa minimnya informasi dan hiburan tetapi memiliki dukungan dari keluarga yang cukup lebih baik dibandingkan dikota yang lebih berpihak pada aktifitas rutin yang dapat menghambat kerja hormone yang bisa menimbulkan stress bahan depresi pada ibu nifas.

Wilayah kerja Puskesmas Allu Polewali Mandar merupakan salah satu puskesmas yang berada di Kabupaten Polewali Mandar yang termasuk daerah pedesaan. Wilayahnya meliputi 1 kelurahan dan 6 desa dengan sebagian penduduk adalah masyarakat Suku Mandar yang berjarak 1,5 jam dari pusat kota. Sedangkan Puskesmas Pekkabata terletak di daerah perkotaan yang terdiri dari 4 kelurahan, dengan sebagian penduduk adalah masyaraat campuran yang berada di tengah kota Kabupaten Polewali Mandar. Peneliti telah melakukan survei awal dengan menggunakan kuesioner baku post partum blues kepada 4 orang ibu nifas di wilayah kerja Puskesmas Allu dan didapatkan hasil bahwa terdapat 2 orang yang mengalami post partum blues. Sedangkan data survei awal di wilayah kerja Puskesmas Pekkabata dari 4 orang ibu nifas terdapat 1 orang yang mengalami post partum blues.

Tujuan khusus dari penelitian adalah untuk mengetahui seberapa banyak kejadian post partum blues di wilayah kerja Puskesmas Allu Kabupaten Polewali Mandar Tahun 2020, untuk mengetahui seberapa banyak kejadian post partum blues di wilayah kerja Puskesmas Pekkabata Kabupaten Polewali Mandar Tahun

Samria, Indah Haerunnisa (Perbandingan kejadian post partum blues pada ibu nifas....) 
2020, dan untuk mengetahui perbandingan kejadian post partum blues pada ibu nifas di wilayah kerja Puskesmas Allu dengan Puskesmas Pekkabata Kabupaten Polewali Mandar Tahun 2020.

\section{METODE}

Penelitian ini merupakan penelitian kuantitatif, dengan menggunakan desain penelitian deskriptif komparatif dan pendekatan cross-sectional. Teknik pengumpulan data pada penelitian ini menggunakan lembar kuesioner. Untuk mengukur kejadian post partum blues, peneliti menggunakan Edinburgh Postnatal Depression Scale (EPDS) yang telah baku. EPDS berupa kuesioner yang terdiri dari 10 pertanyaan mengenai bagaimana perasaan pasien dalam satu minggu pasca melahirkan. Teknik pengambilan sampel yang digunakan pada penelitian ini menggunakan purposive sampling dengan jumlah sampel sebanyak 40 orang ibu post partum yang terdiri dari 20 orang ibu post partum di wilayah kerja Puskesmas Pekkabata dan 20 orang ibu post partum di wilayah kerja Puskesmas Allu.

\section{HASIL DAN PEMBAHASAN}

Table 1. Karakteristik responden menurut usia

\begin{tabular}{ccc}
\hline Usia & Jumlah Responden & Persentase (\%) \\
\hline 20-30 Tahun & 24 & 60 \\
\hline 31-40 Tahun & 12 & 30 \\
\hline$>$ 40 Tahun & 4 & 10 \\
\hline Jumlah & $\mathbf{4 0}$ & $\mathbf{1 0 0}$ \\
\hline
\end{tabular}

Sumber : data primer 2020

Berdasarkan tabel 1 diperoleh hasil bahwa dari 40 responden jumlah ibu dengan rentang umur 20-30 tahun sebanyak 24 orang (60\%), umur 31-40 tahun sebanyak 12 orang $(30 \%)$ dan umur $>40$ tahun sebanyak 4 orang $(10 \%)$.

Tabel 2. Karakteristik responden menurut tingkat Pendidikan

\begin{tabular}{|c|c|c|}
\hline Pendidikan & Jumlah Responden & Persentase (\%) \\
\hline Tidak tamat SD & 2 & 5 \\
\hline SD & 12 & 30 \\
\hline SMP & 6 & 15 \\
\hline SMA & 10 & 25 \\
\hline PT & 0 & 0 \\
\hline Total & 40 & 100 \\
\hline
\end{tabular}


Berdasarkan Tabel 2 menunjukkan bahwa dari 40 responden, jumlah responden yang tidak tamat SD sebanyak 2 orang (5\%), tamat SD sebanyak 12 orang $(30 \%)$, tamat SMP sebanyak 6 orang (15\%), tamat SMA sebanyak 10 orang (25\%) dan tidak ada yang tamat perguruan tinggi.

Tabel 3. Distribusi responden menurut pekerjaan pada ibu

\begin{tabular}{|c|c|c|}
\hline Pekerjaan & Jumlah Responden & Persentase (\%) \\
\hline IRT & 38 & 95 \\
\hline Wiraswasta & 2 & 5 \\
\hline Honorer & 0 & 0 \\
\hline PNS & 0 & 0 \\
\hline Jumlah & 40 & 100 \\
\hline
\end{tabular}

Berdasarkan tabel 3 diperoleh hasil bahwa dari 40 responden, terdapat 38 orang yang bekerja sebagai IRT (95\%), 2 orang yang bekerja sebagai wiraswasta (5\%), dan tidak ada responden yang bekerja sebagai tenaga honorer maupun pegawai negeri sipil (PNS).

Tabel 4. Distribusi responden menurut dukungan suami

\begin{tabular}{ccc}
\hline Dukungan & Jumlah Responden & Persentase (\%) \\
\hline Mendukung & 18 & 45 \\
\hline Tidak Mendukung & 22 & 55 \\
\hline Jumlah & $\mathbf{4 0}$ & $\mathbf{1 0 0}$ \\
\hline
\end{tabular}

Sumber: Data primer 2020

Berdasarkan tabel 4 diperoleh hasil bahwa dari 40 orang responden, jumlah suami responden yang mendukung sebanyak 18 orang $(45 \%)$ dan tidak mendukung sebanyak 22 orang (55\%).

Tabel 5. Distribusi responden menurut kejadian

\begin{tabular}{lcc}
\hline $\begin{array}{l}\text { Kejadian Post } \\
\text { Partum Blues }\end{array}$ & Jumlah Responden & Persentase (\%) \\
\hline Menderita & 22 & 55 \\
\hline Tidak Menderita & 18 & 45 \\
\hline Jumlah & $\mathbf{4 0}$ & $\mathbf{1 0 0}$ \\
\hline Sumber: Data primer 2020 &
\end{tabular}

Berdasarkan tabel 5 diperoleh hasil bahwa dari 40 orang responden, sebagian besar responden menderita post partum blues sebanyak 22 orang (55\%) dan tidak menderita post partum blues sebanyak 18 orang $(45 \%)$.

Samria, Indah Haerunnisa (Perbandingan kejadian post partum blues pada ibu nifas....) 
Tabel 6. Perbandingan kejadian post partum blues pada ibu nifas wilayah kerja Puskesmas Allu dengan ibu nifas wilayah kerja Puskesmas Pekkabata, Polewali Mandar

\begin{tabular}{|c|c|c|c|c|c|c|c|}
\hline \multirow[b]{2}{*}{$\begin{array}{c}\text { Kejadian } \\
\text { post partum } \\
\text { blues }\end{array}$} & \multicolumn{4}{|c|}{ Wilayah } & \multicolumn{3}{|c|}{$\%$} \\
\hline & $\begin{array}{c}\text { Masyarakat } \\
\text { Perdesaan } \\
\text { (Puskesmas } \\
\text { Allu) } \\
\end{array}$ & $\%$ & $\begin{array}{c}\text { Masyarakat } \\
\text { Perkotaan } \\
\text { (Puskesmas } \\
\text { Pekkabata } \\
\end{array}$ & $\%$ & Total & & $\begin{array}{c}P- \\
\text { Value }\end{array}$ \\
\hline Menderita & 8 & $20 \%$ & 14 & $35 \%$ & 22 & $55 \%$ & \multirow{3}{*}{$\begin{array}{l}0,038 \\
<0,05\end{array}$} \\
\hline $\begin{array}{c}\text { Tidak } \\
\text { Menderita }\end{array}$ & 11 & $\begin{array}{c}27,5 \\
\%\end{array}$ & 7 & $17,5 \%$ & 18 & $45 \%$ & \\
\hline Total & 19 & $\begin{array}{c}47,5 \\
\%\end{array}$ & 21 & $52,5 \%$ & 40 & $100 \%$ & \\
\hline
\end{tabular}

Sumber: Hasil penelitian tahun 2020

Berdasarkan tabel 6 hasil tabulasi silang kejadian post partum blues pada ibu nifas antara wilayah kerja Puskesmas Allu dan wilayah kerja Puskesmas Pekkabata Kabupaten Polewali Mandar, didapatkan bahwa dari 20 responden masyarakat pedesaan yang menderita post partum blues sebanyak 8 responden $(20 \%)$ dan yang tidak menderita post partum blues sebanyak 11 responden (27,5\%). Di wilayah perkotaan yang menderita post partum blues sebanyak 14 responden $(35 \%)$ dan yang tidak menderita post partum blues sebanyak 7 responden $(17,5 \%)$.

Hasil analisis hubungan dengan menggunakan uji statistik chi-square didapatkan signifikansi dari hubungan kedua variabel tersebut adalah $p=0,000<\alpha$ $(0,05)$ yang berarti bahwa Ha diterima dan Ho ditolak, sehingga ada perbedaan antara kejadian post partum blues pada ibu nifas wilayah kerja Puskesmas Allu dengan ibu nifas wilayah kerja Puskesmas Pekkabata Kabupaten Polewali Mandar. Dari hasil penelitian didapatan bahwa dari 40 responden, sebagian besar responden tidak menderita post partum blues yaitu sebanyak 18 responden (55\%) dan jumlah responden yang menderita post partum blues sebanyak $22(45 \%)$.

Berdasarkan penelitian yang dilakukan terdapat 22 responden yang mengalami post partum blues di mana diantaranya yaitu 8 orang di wilayah kerja Puskesmas Allu dan 14 orang di wilayah kerja Puskesmass Pekkabata. Sebagian responden mengalami post partum blues sejak dua hari setelah melahirkan. Responden tersebut sering melamun, tidak mau makan serta merasa tidak mampu mengurus bayinya. Hal ini dikarenakan kurangnya dukungan dari keluarga baik suami maupun ibunya dalam memperhatikan keluh kesah responden setelah melahirkan.

Post Partum Blues dipengaruhi oleh umur hal ini dapat ditunjukan dari data bahwa sebagian besar responden ibu berumur $<20$ tahun sebanyak 2 orang (25\%), umur 21-35 tahun sebanyak 5 orang (62,5\%) dan umur $>35$ tahun sebanyak 1 orang $(15,5 \%)$. Sejarah kehamilan adalah faktor utama yang bisa

Samria, Indah Haerunnisa (Perbandingan kejadian post partum blues pada ibu nifas....) 
menimbulkan terjadinya post partum blues. Riwayat seperti kehamilan yang tidak diinginkan pada ibu dengan usia mudah, adanya problem dengan orang tua atau mertua, kurangnya biaya untuk persalinan, kurangnya perhatian yang diberikan pada si ibu dan faktor dari etiologi serta faktor pesiolog lainya merupakan penyebab utama post partum blues.

Post Partum Blues atau gangguan mental pasca persalinan sering kali ditangani dan baik. Banyak ibu yang berjuang sendiri dalam beberapa saat setelah melahirkan. Mereka merasakan ada suatu hal yang salah namun mereka sendiri tidak benar-benar mengetahui apa yang sedang terjadi. Apabila mereka pergi mengunjungi dokter atau sumber-sumber lainya untuk minta pertolongan, seringkali hanya mendapatan saran untuk beristirahat atau tidur lebih banyak, tidak gelisah, minum obat atau berhenti mengasihani diri sendiri dan mulai merasa gembira menyambut kedatangan bayi yang mereka cintai.

Dapat menigkatkan mutu pelayanan kesehatan khususnya pada ibu nifas(pasca persalinan) dan menigkatkan derajat kesehatan pada ibu nifas secara optimal dan dapat memperluas wawasan dengan cara memberikan penyuluhan kepada ibu nifas sehingga resiko post partum blues dapat dicegah secara maksimal

Pada ibu post partum diwilayah kerja Puskesmas Massenga dan Puskesmas Tutallu agar ibu pasca melahirkan dapat mengetahui tentang post partum blues dan lebih maksimal mempersiapkan diri menjadi seorang ibu sehingga post partum blues tidak terjadi.

Rencana selanjutnya akan meneliti implementasi pendeteksian postpartum berbasis media sosial.Dapat memberikan penyuluhan dan pendidikan kesehatan kepada ibu nifas sehingga resiko post partum blues dapat dicegah secara lebih baik.

\section{SIMPULAN}

Hasil penelitian menggunakan uji chi-square diperoleh hasil bahwa $p$ value $=0,038<\alpha(0,05)$ sehingga dapat disimpulkan bahwa ada perbedaan kejadian post partum blues ibu nifas antara wilayah kerja Puskesmas Pekkabata (perkotaan) dan wilayah kerja Puskesmas Allu (pedesaan) di Kabupaten Polewali Mandar. Kejadian post partum blues di wilayah perkotaan lebih besar dari kejadian post partum blues di wilayah pedesaan.

\section{DAFTAR PUSTAKA}

Anggraini, Y., 2010 . Asuhan Kebidanan Nifas. Yogyakarta : Pustaka Rihama

Anik maryunani., 2017 Asuhan Kebidana Nifas. Yogyakarta : Pustaka Rihama

Samria, Indah Haerunnisa (Perbandingan kejadian post partum blues pada ibu nifas....) 
Ariyani, Debby Utami Siska.,2014. Analisis faktor determinan yang berhubungan dengan masalah psikologis postpartum blues : Jurnal Kesehatan Bina Husada

Bahiyatun, 2009. Buku ajar asuhan kebidanan nifas normal. Jakarta : Penerbit buku kedokteran EcG

Damayanti, Ika P., Maita, L, Triana, A, Afni, R., 2014. Buku ajar asuhan kebidanan komrehensif pada ibu bersalin dan bayi baru lahir. Yogyakarta : penerbit Deepublish.

Damaiyanti, Ika, P., Sundawati, D, 2014. Asuhan Kebidanan Masa Nifas . Bandung : PT Refika Aditama

Erni Hernawati \& Lia Kamila. 2017

Dewi, Vivian Nanny Lia., \& Sunarsih, Tri., 2011 . Asuhan kebidanan pada ibu Nifas. Jakarta : Salemba Medika

Fatmawati, Diah Ayu., 2015 Faktor risiko yang berpengaruh terhadap kejadian postpartum Blues. Fakultas Ilmu kesehatan : Universitas Pesantren Tinggi Darul Ulum Jombang

Ibrahim Fatmah., Rahma., \& Muhammad Ikhsan., 2012. Faktor - faktor yang berhubungan dengan depresi postpartum di RSIA Pertiwi Makassar tahun : Mahasiswa Biostatistik/ KKB FKM Unhas

Irawati, Dian., Farida Yuliani., 2014. Pengaruh Faktor Psikososial dan cara persalinan terhadap terjadinya post partum blues pada ibu nifas. Mojokerto : Studi di Ruang Nifas RSUD R.A Bosoeni Mojokerto

Machmudah., 2010 Pengaruh Persalinan Dengan Komplikasi Terhadap Kemunginan Terjadinya Post Partum Blues Di Kota Semarang. Tesis. Fakulitas Ilmu Keperawatan Program Magister Ilmu Keperawatan Depok UI

Nursalam, Dkk., 2008. Asuhan keperawatan Bayi dan anak untuk perawat dan bidan. Jakarta : Salemba Medika

Riyanto, Agus., 2011. Aplikasi Metodologi Penelitian Kesehatan. Yogyakarta : Nuha Medika

Rukiyah, Ai Yeyeh., Yulianti, Lia, Liana, Meida., 2010. Asuhan Kebidanan III . jakarta : Trans Info MedikaA

Th. Endang Purwoastutu \& Elisabeth Walyani, 2015. 